\title{
Retrieval-induced forgetting and mental imagery
}

\author{
Jo Saunders, Marcelle Fernandes, and Liv Kosnes \\ Swansea University, Swansea, Wales
}

\begin{abstract}
In the present article, we present four experiments in which we examined whether mental imagery can initiate retrieval-induced forgetting. Participants were presented with word pairs (Experiments 1, 2, and 3) or narratives (Experiment 4) and then engaged in selective mental imagery about half of the details from half of the categories. The results indicated that mental imagery can produce the same pattern of impairment as retrieval practice (Experiment 1) and postevent questioning (Experiment 4). Additionally, mental imagery-invoked, retrievalinduced forgetting was found for category cued recall (Experiments 1, 3, and 4) and cued recall (Experiment 2); it was found to dissipate across a $24-\mathrm{h}$ delay, but only when there was no pre-delay test (Experiment 3 ). Such retrieval-induced forgetting was also found for imagining from the first-person and third-person perspectives (Experiment 4). From these findings, we suggest that the underlying retrieval processes behind mental imagery can initiate retrieval-induced forgetting. The findings are discussed in terms of inhibitory processes.
\end{abstract}

Retrieval has been found to be a potent method for modifying memory that is typically associated with later facilitated memory performance of that information both at short and longer delays (Bjork \& Bjork, 1992). Retrieval can be found in numerous memory tasks, such as cued recall, postevent questioning, questionnaires, and surveys collecting personal data. More recently, however, retrievalbased tasks have also been associated with more negative memory-modifying properties. Such negative effects typically occur as a consequence of retrieving other items from memory (see, e.g., Anderson, R. A. Bjork, \& E. L. Bjork, 1994). For example, during many everyday memory tasks, one may attempt to retrieve a desired memory from a larger category of related information, such as one's current telephone number from the category of all previously held numbers. So that we may complete this task quickly and efficiently, the related-but-unwanted memories may be pushed out of conscious awareness to prevent them from competing for retrieval and disrupting the successful retrieval of the desired memory. Whereas we may then be able to complete the current processing goal (i.e., the retrieval of the desired memory), the related-but-unwanted memories may remain unavailable for retrieval for some time afterward; that is, if we then wish to retrieve one of those previously unwanted memories, we may find it difficult to do so. This failure to retrieve previously related-but-unwanted memories is known as retrieval-induced forgetting.

Both the facilitatory effects of retrieval and its negative consequences are typically examined using the retrieval practice paradigm. In a retrieval practice task, participants study categories of related information (e.g., fruitapple, fruit-banana; sport-golf, sport-hockey) and are then prompted to retrieve a subset of items from a subset of categories using guided retrieval practice (e.g., fruit-ap
This selective retrieval typically produces three types of items: practiced items from practiced categories (i.e., fruitapple), unpracticed items from practiced categories (i.e., fruit-banana), and items from unpracticed categories (i.e., sports). In the final task, the processing goal shifts from selective to global retrieval, and participants' memory is tested for all items from all categories, typically using either cued or free recall. The retrieval practice paradigm typically produces two patterns of recall: (1) Memory performance for practiced items from practiced categories (i.e., $\mathrm{Rp}+$ items) is facilitated, whereas that for unpracticed category items (i.e., Nrp items) is not; and (2) memory performance for unpracticed items from practiced categories (i.e., $\mathrm{Rp}-$ items) is impaired, relative to that for Nrp items (i.e., retrievalinduced forgetting). Such effects have also been found in impression formation (MacLeod \& Macrae, 2001; Macrae \& MacLeod, 1999), eyewitness events (MacLeod, 2002; Shaw, Bjork, \& Handal, 1995), autobiographical memory (Barnier, Hung, \& Conway, 2004), and second-language acquisition (Levy, McVeigh, Marful, \& Anderson, 2007), suggesting the applicability of retrieval-induced forgetting to a wide variety of information processing scenarios.

It has been suggested that the possible mechanisms underlying retrieval-induced forgetting may be inhibitory in nature. The inhibitory account suggests that inhibitory processes may be initiated in response to high levels of retrieval competition emanating from the $\mathrm{Rp}-$ items. Specifically, during retrieval practice, the presentation of a memorial prompt (e.g., FRUIT-B___ to retrieve the target item (e.g., banana) leads to other related-but-unwanted items competing for retrieval (e.g., blackberry, blueberry). In order to combat this unwanted interference, inhibitory processes are brought to bear on the Rp - items, suppressing their levels of activation below baseline. On an im- 
mediate test, participants are able to remember the $\mathrm{Rp}+$ items but not the Rp- items (see Anderson, E. L. Bjork, \& R. A. Bjork, 2000; Anderson et al., 1994; Anderson \& Spellman, 1995).

A number of findings are consistent with the inhibitory account. First, retrieval-induced forgetting has been found to be cue independent; that is, retrieval-induced forgetting persists even when a retrieval cue different from the one used during retrieval practice is used at test. The finding that retrieval-induced forgetting is cue independent suggests that the memorial representation of the $\mathrm{Rp}-$ item is suppressed below baseline levels of activation, rather than there being noninhibitory associative interference occurring at the level of the retrieval route (Anderson \& Bell, 2001; Anderson \& Spellman, 1995; Camp, Pecher, \& Schmidt, 2005; MacLeod \& Saunders, 2005; Saunders \& MacLeod, 2006).

A second finding that is consistent with the inhibitory account is that retrieval-induced forgetting is dependent on the strength of the competitor (Anderson et al., 1994; Saunders, 2009). Specifically, retrieval-induced forgetting occurs only when the competing items are strong (as measured by taxonomic strength). Strong items are more likely to come to mind during retrieval practice and thus interfere with the retrieval of the target item. Weak items, on the other hand, are less likely to come to mind during retrieval practice and are, therefore, weaker competitors. In the latter case, retrieval-induced forgetting is less likely to be needed for promoting the successful retrieval of the target.

Third, retrieval-induced forgetting has been found to be a recall-specific process; that is, the active retrieval of the $\mathrm{Rp}+$ items is required in order to initiate retrieval-induced forgetting (e.g., Fruit-ap___ Anderson et al., 2000). Conversely, retrieval-induced forgetting is absent when the $\mathrm{Rp}+$ items are re-presented (e.g., FR___apple). Representation may not initiate retrieval-induced forgetting because the presentation of the target item presents sufficient cue-related material to allow for the specific retrieval of the target without also activating related-but-unwanted items. The finding that re-presentation is insufficient for initiating retrieval-induced forgetting is of significance to the present experiments. Specifically, when an individual is asked to form mental imagery, such as of an apple, a degree of re-presentation of the target item occurs. The difference, however, between re-presentation of the verbal information fruit-apple and the mental imagery of an apple is that mental imagery requires the retrieval of semantic information about the to-be-visualized item (e.g., its color, shape, and/ or taste). Thus, it may be the case that re-presentation that induces covert or overt retrieval may still be sufficient for initiating retrieval-induced forgetting. On the other hand, re-presentations that are absent of covert or overt retrieval should not initiate retrieval-induced forgetting.

Since mental imagery requires the access of semantic knowledge, it is likely to initiate retrieval-induced forgetting. Previous work by Bäuml (2002) has suggested that semantic generation can lead to retrieval-induced forgetting; that is, semantically generating new exemplars of a category can impair memory for other, previously studied members (see also Storm, Bjork, Bjork, \& Nestojko, 2006). The work of
Bäuml and Hartinger (2002) and that of Storm et al. suggest that retrieval from semantic memory can impair memory for competing items (see also Johnson \& Anderson, 2004). Thus, if mental imagery requires the generation of semantic information about to-be-visualized items, mental imagery is likely to lead to retrieval-induced forgetting. On the other hand, if mental imagery does not require the generation of semantic information from long-term memory, it may be more akin to a passive re-presentation task; thus, retrievalinduced forgetting will not occur.

The aim of the present research, therefore, is to determine whether mental imagery can initiate retrievalinduced forgetting. If mental imagery utilizes the same retrieval processes as other memory tasks, this suggests that the act of visualizing may have the same ability to initiate retrieval-induced forgetting. If mental imagery can impair memory for nonvisualized-but-related details (i.e., $\mathrm{Rp}-$ items), this would suggest that mental imagery can be used as a memory task to modify memory and that the underlying process may be retrieval based. In order to examine this issue, in Experiment 1, mental imagery will be compared against known retrieval (i.e., retrieval practice) and re-presentation tasks to determine whether mental imagery produces the same patterns of impairment.

\section{EXPERIMENT 1 Does Mental Imagery Evoke Retrieval-Induced Forgetting?}

\section{Method}

Participants and Design. Sixty-three students from Swansea University participated in exchange for $£ 5$. The experiment had a 3 (practice: mental imagery, retrieval practice, or re-presentation) $\times$ 3 (item type: $\mathrm{Rp}+, \mathrm{Rp}-$, or Nrp) mixed design with repeated measures on the latter factor. Each condition contained 21 participants.

Materials and Procedure. Upon arrival at the laboratory, participants were randomly assigned to one of the conditions and were presented with a booklet containing a single cue-item word pair at the top of each page. There were eight semantic categories (sports equipment, tools, bird, weapon, flower, drinks, fruit, and musical instrument) containing six items each (see Appendix A). Participants were given $5 \mathrm{sec}$ to study each cue-exemplar pairing. Order of presentation was randomized across participants. Participants in the mental imagery condition were then presented with a booklet containing visual imagery tasks for half of the items from half of the categories (i.e., three items from four categories). The cue-exemplar pair was presented at the top of the page with an instruction to participants to form an image in their mind of an aspect of the object. Four aspects were formed for each object (see Appendix B), with one aspect visualized per task (i.e., four aspects visualized across four tasks). Shape, color, and size were visualized for all and practiced individually for the first three mental imagery tasks; for the final (i.e., fourth) mental imagery task, participants were prompted to think of the sound, texture, weight, smell, or taste of the item. Order of items to undergo mental imagery was randomized across each of the four tasks and across participants. The participants were given $10 \mathrm{sec}$ to visualize each object. They also rated the vividness of their mental imagery using a variation of the scale from the Vividness of Visual Imagery Questionnaire (VVIQ; Marks, 1973), which ranges from 1 (no image at all, you only "know" that you are thinking of an object) to 5 (perfectly clear and as vivid as normal vision). (Note that we reversed the scale on the VVIQ to make it more intuitive.) Each set of mental imagery tasks was interleaved with a distractor task (i.e., anagrams) of increasing duration (i.e., 1, 2, 3 , and $4 \mathrm{~min}$ ) in order to increase the difficulty of the task (Landauer \& Bjork, 1978; MacLeod, 2002). 
The retrieval practice condition followed the same procedure, except that the participants were presented with the category cue and unique two-letter or three-letter word stem for half of the items from half of the categories and had to write both the cue and the item on a response sheet (e.g., BIRD-bu___ ) The re-presentation condition followed a similar procedure, except that the participants were re-presented with the item and had to retrieve the cue (e.g., BI___budgie). Each item was also practiced four times. Finally, all of the participants completed a category cued recall task, whereby each category was presented to the participants and they had to free-recall category members. Upon completion of the task, the participants were thanked, debriefed, and dismissed.

\section{Results}

Retrieval practice success rates. The proportion of items successfully practiced during the retrieval practice and re-presentation tasks was .95 in both conditions. Mean visual imagery vividness, as determined by using the VVIQ in the mental imagery condition, was 4.38 , indicating that participants generated vivid mental images during the tasks.

Facilitation effects. Forming mental imagery improved memory for those visualized items $(M=.93)$ more than it did for items from nonvisualized categories $(M=.37)$ (see Table 1). Likewise, retrieval practice also facilitated memory performance (for Rp+ items, $M=.90$; for Nrp items, $M=.41$ ), as did re-presentation (for Rp + items, $M=.87$; for Nrp items, $M=.38$ ). The recall scores within each condition were transformed using an arcsine transformation in order to establish homogeneity of variance (see Snedecor \& Cochran, 1980, pp. 290-291). A 3 (practice: mental imagery, retrieval practice, or re-presentation $) \times 2(\mathrm{Rp}+$ or $\mathrm{Nrp})$ mixed ANOVA was conducted and revealed a significant effect of item type $\left[F(1,60)=436.97, M S_{\mathrm{e}}=19.52, p<\right.$ $.001, \eta^{2}=.87$ ], suggesting that practice improved memory for $\mathrm{Rp}+$ items, relative to that for Nrp items. However, no item $\times$ practice interaction was detected $[F(1,60)=1.22$, $\left.M S_{\mathrm{e}}=0.05, \mathrm{n} . \mathrm{s}.\right]$, suggesting that mental imagery, retrieval practice, and re-presentation improved memory for $\mathrm{Rp}+$ items to a similar degree. Follow-up paired-samples $t$ tests indicated that mental imagery significantly improved memory for $\mathrm{Rp}+$ items, relative to that for Nrp items $[t(20)=14.89, p<.001]$, retrieval practice significantly improved memory for $\mathrm{Rp}+$ items, relative to that for Nrp items $[t(20)=10.74, p<.001]$, and that re-presentation improved $\mathrm{Rp}+$ performance $[t(20)=11.11, p<.001]$.

Retrieval-induced forgetting. Mental imagery also impaired memory for nonvisualized items from visual-

Table 1

Mean Recall Performance by Condition, As a Function of Item Type in Experiment 1

\begin{tabular}{|c|c|c|c|c|c|c|c|}
\hline \multirow[b]{3}{*}{ Practice Task } & \multicolumn{6}{|c|}{ Item Type } & \multirow{3}{*}{$\begin{array}{l}\text { Retrieval- } \\
\text { Induced } \\
\text { Forgetting* }\end{array}$} \\
\hline & \multicolumn{2}{|c|}{$\mathrm{Rp}+$} & \multicolumn{2}{|c|}{$\mathrm{Rp}-$} & \multicolumn{2}{|c|}{ Nrp } & \\
\hline & $M$ & $S D$ & $M$ & $S D$ & $M$ & $S D$ & \\
\hline Mental imagery & .93 & .05 & .06 & .08 & .37 & .16 & -.31 \\
\hline Retrieval practice & .90 & .08 & .24 & .15 & .41 & .16 & -.17 \\
\hline Re-presentation & .87 & .23 & .41 & .19 & .38 & .19 & +.03 \\
\hline
\end{tabular}

Note-Rp+, practiced items from practiced categories; Rp-, unpracticed items from practiced categories; Nrp, unpracticed items from unpracticed categories. ${ }^{*}(\mathrm{Rp}-)-\mathrm{Nrp}$. ized categories $(M=.06)$, as compared with memory for nonvisualized categories, as did retrieval practice (mean $\mathrm{Rp}-=.24)$, but re-presentation did not $(M=.41)$. A 3 (practice: mental imagery, retrieval practice, or representation $) \times 2(\mathrm{Rp}-$ or Nrp) mixed ANOVA detected a significant main effect of item type $[F(1,60)=17.16$, $\left.M S_{\mathrm{e}}=0.64, p<.001, \eta^{2}=.16\right]$, suggesting that practice impaired memory for nonpracticed items from practiced categories (i.e., Rp - items). A significant interaction was also detected between item and type of practice $[F(1,60)=$ $7.78, M S_{\mathrm{e}}=0.29, p<.001, \eta^{2}=.17$ ], suggesting that the different practice tasks led to different levels of impairment of Rp - items. Follow-up paired-samples $t$ tests indicated that mental imagery significantly reduced recall of $\mathrm{Rp}-$ items, as compared with recall of Nrp items $[t(20)=$ $-4.30, p<.001]$ and that retrieval practice also impaired memory for Rp - items $[t(20)=-3.29, p<.01]$, but that re-presentation did not $[t(20)=0.71$, n.s. $]$.

Output interference. Category cued recall tests can be vulnerable to output interference, whereby stronger $\mathrm{Rp}+$ items are outputted during recall first and may block the later recall of weaker Rp - items (Roediger \& Schmidt, 1980). If output interference influences recall, then retrieval-induced forgetting may be evident only for participants who retrieve $\mathrm{Rp}+$ items early during free recall. To determine whether retrieval-induced forgetting was due to output interference, we followed the procedure outlined by Macrae and MacLeod (1999; see also MacLeod \& Macrae, 2001; Saunders \& MacLeod, 2002). Each participant received a score that indicated the degree to which free recall began with $\mathrm{Rp}+$ or $\mathrm{Rp}-$ items. This score was calculated by subtracting the mean recall position of $\mathrm{Rp}+$ items from that of Rp - items. Negative scores indicated early $\mathrm{Rp}$ - recall; positive scores represented early $\mathrm{Rp}+$ recall. Scores were then ranked from highest to lowest, and retrieval-induced forgetting effects were then calculated. The mean retrieval-induced forgetting effects following mental imagery that were demonstrated by the early $\mathrm{Rp}+$ group $(M=-.38)$ were larger than those demonstrated by the early $\mathrm{Rp}-\operatorname{group}(M=$ $-.26)$; however, this difference did not reach significance $[t(19)=1.48$, n.s. $]$. No differences were detected between the early $\mathrm{Rp}+(M=-.19)$ and early $\mathrm{Rp}-(M=-.15)$ groups for the retrieval practice condition $[t(19)=0.42$, n.s.]. Output interference was therefore unlikely to have significantly contributed to the retrieval-induced forgetting effects found following mental imagery or retrieval practice.

Vividness ratings and retrieval-induced forgetting. Vividness ratings were also examined to determine whether mean vividness was related to the level of retrieval-induced forgetting - that is, whether higher vividness scores led to more retrieval-induced forgetting. An inhibition score (i.e., $[\mathrm{Rp}-]-\mathrm{Nrp}$ ) was calculated for each participant. Vividness ratings were then ranked from lowest to highest. The level of inhibition in the mental imagery condition for low imagers $(M=-.27)$ was found not to be significantly different from that for high imagers $(M=-.37)[t(19)=$ 1.26, n.s.]. Therefore, higher vividness ratings do not lead to significantly higher retrieval-induced forgetting effects. 


\section{Discussion}

Mental imagery produced the same patterns of remembering (i.e., $\mathrm{Rp}+>\mathrm{Nrp}$ ) and forgetting (i.e., $\mathrm{Rp}-<\mathrm{Nrp}$ ) as those produced by retrieval practice. Because retrieval practice is a known retrieval-based task, the finding that mental imagery impairs memory for nonvisualized items from visualized categories suggests that visual imagery can be used as a memory-based task. Conversely, mental imagery did not mimic the pattern of results that representation displayed, despite mental imagery's requiring the re-presentation of the cue-exemplar pair. This finding suggests that re-presentation can, under some circumstances, initiate retrieval-induced forgetting; that is, when re-presentation requires covert retrievals, such as those found in the mental imagery task, it may initiate retrieval processes that lead to increased competition between target items and their competitors.

\section{EXPERIMENT 2 Cued Recall Task}

In Experiment 1, a category cued recall procedure was used to measure memory of word pairs. Although retrieval-induced forgetting was found not to be due to output interference, the trend was in the direction of larger retrieval-induced forgetting effects when $\mathrm{Rp}+$ items were outputted first. To ensure that mental imagery-invoked, retrieval-induced forgetting is not due to the early output of stronger Rp + items blocking recall of weaker $\mathrm{Rp}$ - items, a cued recall procedure, in which $\mathrm{Rp}-$ items will be cued before $\mathrm{Rp}+$ items, will be used in Experiment 2.

\section{Method \\ Participants and Design. Twenty students from Swansea Uni- versity participated in exchange for $£ 5$ or course credit. The experi- ment was a single-factor design (item type: $\mathrm{Rp}+, \mathrm{Rp}-$, or Nrp). \\ Materials and Procedure. In Experiment 2, we used the same materials and procedure as in Experiment 1, with the exception of the final memory task. We used a cued recall task, in which participants were presented with the category cue and a unique letter prompt. To produce unique cue-plus stems, the majority of stems were one let- ter, some were two letters (i.e., pitchfork, pliers, champagne, coffee, flute, French horn), and some were three letters (i.e., bowling, box- ing, cactus, carnation, daisy, daffodil). The participants were given a booklet containing one item from each category presented on each page, and they had $7 \mathrm{sec}$ to complete each item, as timed by an elec- tric metronome. $\mathrm{Rp}-$ items were cued before $\mathrm{Rp}+$ items.}

\section{Results and Discussion}

Mean visual imagery vividness using the VVIQ in the mental imagery condition was 4.33 , indicating that participants had generated vivid mental images during the tasks. Visualized items $(M=.94)$ were remembered more than were items $(M=.40)$ from the nonvisualized category $[t(20)=14.04, p<.001]$, and nonvisualized items from the visualized category $(M=.07)$ were reported less often than were Nrp items $[t(20)=-9.23, p<.001]$. Thus, mental imagery-invoked, retrieval-induced forgetting remains active, even when weaker $\mathrm{Rp}-$ items are cued before stronger $\mathrm{Rp}+$ items. Finally, no significant difference was detected in the level of retrieval-induced forgetting between low $(M=-.27)$ and high $(M=-.39)$ imagers $[t(19)=1.68$, n.s. $]$.

\section{EXPERIMENT 3 Effects of Delay on Mental Imagery}

The endurance of retrieval-induced forgetting has been debated in recent years. Some researchers (MacLeod \& Macrae, 2001; Saunders \& MacLeod, 2002) propose the utility of an inhibitory mechanism that endures for only a small period of time after retrieval. Others (e.g., Anderson, 2001) have suggested that there are situations in which it may be useful for inhibition to be longer lasting.

A number of studies have examined the effects of delay on retrieval-induced forgetting. Studies by Carroll, Campbell-Ratcliffe, Murnane, and Perfect (2007), MacLeod and Macrae (2001), and Saunders and MacLeod (2002) found that retrieval-induced forgetting dissipates when the retrieval practice and test phases are separated by 24 h. Conroy and Salmon $(2005,2006)$ and Ford, Keating, and Patel (2004) found that retrieval-induced forgetting is present after $24 \mathrm{~h}$, even though retrieval practice was spaced across several days. Further studies have found that significant retrieval-induced forgetting persists at 24-h (Migueles \& García-Bajos, 2007) and 1-week delays (Storm et al., 2006); however, memory for all items was tested on two separate occasions: directly after retrieval practice and after a lengthy delay. Only one study (GarcíaBajos, Migueles, \& Anderson, 2009) has used the same methodology as MacLeod and Macrae's, and they found significant retrieval-induced forgetting after a 1-week delay (i.e., they tested memory only once, and all the retrieval practice tasks occurred on the same day).

Methodological differences may be why the effects of a delay on retrieval-induced forgetting are not consistent across the aforementioned studies. For example, in some studies, spaced practice across several days may have had a cumulative effect on retrieval-induced forgetting. Likewise, in other studies, testing memory before and after a delay may have led participants to use a memory strategy on the second test (such as thinking back to the first test) to remind them of the items.

In the present study, therefore, we examined the effects of delay on mental imagery-initiated, retrieval-induced forgetting. We used the same methodology as that used by MacLeod and Macrae (2001) and contrasted it with the methodology used by Migueles and García-Bajos (2007) and Storm et al. (2006). Specifically, the mental imagery and final test will be separated by $24 \mathrm{~h}$ in one condition (MacLeod \& Macrae, 2001); in a second condition, a predelay test will be issued, as will another memory test, after 24 h (Migueles \& García-Bajos, 2007; Storm et al., 2006). If the presence of a pre-delay test is an important factor in the maintenance of retrieval-induced forgetting across a delay, then retrieval-induced forgetting should be present in the pretest-delay condition and not in the condition in which memory is tested only once (i.e., after the delay). 


\section{Method}

Participants and Design. Sixty students from Swansea University participated in exchange for $£ 5$ or course credit. The experiment had a 3 (delay: none, 24 -h, or retest) $\times 3$ (item: $\mathrm{Rp}+, \mathrm{Rp}-$, or Nrp) mixed design with repeated measures on the latter factor. Each condition contained 20 participants.

Materials and Procedure. The materials and procedure were identical to those in Experiment 1, with the exception of the timing of the test for the 24-h delay and retest conditions. In the former condition, the 24-h delay occurred prior to the final test; in the latter condition, the participants completed the test after mental imagery and again after a $24-\mathrm{h}$ delay. In the no-delay condition, the final test occurred in the same testing session as did the mental imagery phase. The mental imagery practice task, distractors, and category cued recall task were all identical to those in Experiment 1.

\section{Results}

Study and picture-naming practice success rates. Mean visual imagery vividness was 4.72 in the no-delay condition, 4.45 in the 24-h delay condition, and 4.61 in the retest condition, indicating that participants generated vivid mental images during the tasks.

Facilitation effects. In order to establish homogeneity of variance, the recall scores within each condition were transformed using an arcsine transformation. To determine whether mental imagery increased recall of imaged items, a 4 (delay: no delay, $24 \mathrm{~h}$, or retest [first test or second test]) $\times 2$ (item status: Rp + or Nrp) mixed ANOVA was conducted (see Table 2). It revealed a significant effect of item type $\left[F(1,38)=391.83, M S_{\mathrm{e}}=14.83, p<\right.$ $\left..001, \eta^{2}=.57\right]$ and a significant interaction between delay and item type $\left[F(3,38)=3.04, M S_{\mathrm{e}}=0.16, p<.05, \eta^{2}=\right.$ $.05]$, suggesting that $\mathrm{Rp}+$ items were reported at different levels across tasks. Planned comparisons revealed that $\mathrm{Rp}+$ items $(M=.82)$ were recalled at a higher rate than were Nrp items $(M=.38)$ in the 24-h delay condition $[t(19)=7.00, p<.001]$, in the no-delay condition (for $\mathrm{Rp}+, M=.91$; for Nrp, $M=.36)[t(19)=12.84, p<$ $.001]$, in the first test in the retest condition (for $\mathrm{Rp}+$, $M=.89$; for $\mathrm{Nrp}, M=.40)[t(19)=14.21, p<.001]$, and in the second test in the retest condition (for Rp+, $M=$ .78 ; for $\operatorname{Nrp}, M=.35)[t(19)=9.49, p<.001]$.

Retrieval-induced forgetting effects. A 4 (delay: nodelay, 24-h, or retest [first test or second test]) $\times 2$ (item status: $\mathrm{Rp}$ - or Nrp) mixed ANOVA was conducted to determine whether retrieval-induced forgetting was present. The analysis revealed an effect of item type $[F(1,38)=$ 93.02, $\left.M S_{\mathrm{e}}=1.41, p<.001, \eta^{2}=.32\right]$ and an interaction

Table 2

Mean Recall Performance by Condition, As a Function of Item Type in Experiment 3

\begin{tabular}{|c|c|c|c|c|c|c|c|}
\hline \multirow{3}{*}{$\begin{array}{c}\text { Delay } \\
\text { Condition }\end{array}$} & \multicolumn{6}{|c|}{ Item Type } & \multirow{3}{*}{$\begin{array}{l}\text { Retrieval- } \\
\text { Induced } \\
\text { Forgetting }\end{array}$} \\
\hline & \multicolumn{2}{|c|}{$\mathrm{Rp}+$} & \multicolumn{2}{|c|}{$\mathrm{Rp}-$} & \multicolumn{2}{|c|}{$\mathrm{Nrp}$} & \\
\hline & $M$ & $S D$ & $M$ & $S D$ & $M$ & $S D$ & \\
\hline Delay & .82 & .13 & .39 & .08 & .38 & .14 & +.01 \\
\hline No-delay & .91 & .07 & .06 & .08 & .36 & .14 & -.30 \\
\hline Retest (Test 1 ) & .89 & .06 & .08 & .09 & .40 & .10 & -.32 \\
\hline Retest (Test 2) & .78 & .09 & .09 & .09 & .35 & .13 & -.26 \\
\hline
\end{tabular}

Note- $\mathrm{Rp}+$, practiced items from practiced categories; $\mathrm{Rp}-$, unpracticed items from practiced categories; Nrp, unpracticed items from unpracticed categories. ${ }^{*}(\mathrm{Rp}-)-\mathrm{Nrp}$. between item and delay $\left[F(3,38)=14.58, M S_{\mathrm{e}}=0.22\right.$, $p<.001, \eta^{2}=.22$ ], indicating different levels of impairment of Rp - items across conditions. Planned comparisons revealed that fewer $\mathrm{Rp}-$ items $(M=.06)$ than $\mathrm{Nrp}$ items $(M=.36)$ were reported in the no-delay condition $[t(19)=-8.76, p<.001]$, in the first test in the retest condition (for Rp-, $M=.08$; for Nrp, $M=.40$ ) $[t(19)=$ $-12.06, p<.001]$, and in the second test in the retest condition (for Rp-, $M=.09$; for Nrp, $M=.35$ ) $[t(19)=$ $-6.89, p<.001]$; no differences were detected between these items for the 24-h delay condition (for Rp-, $M=$ .39 ; for $\operatorname{Nrp}, M=.38)[t(19)=0.28$, n.s. $]$.

Output interference. Performance in each of the conditions was checked for the influence of output interference. In the no-delay condition, the average retrievalinduced forgetting effects were -.28 in the early $\mathrm{Rp}-$ output group and -.31 in the early $\mathrm{Rp}+$ group. No significant differences were detected between the two groups $[t(18)=0.41$, n.s.]. For the first test in the retest condition, the average retrieval-induced forgetting effect was -.31 in the early $\mathrm{Rp}-$ output group and -.33 in the early $\mathrm{Rp}+$ group $[t(18)=0.31$, n.s. $]$. Conversely, the mean retrievalinduced forgetting effect in the second test of the retest condition was significantly smaller in the early $\mathrm{Rp}-$ group $(M=-.13)$ than that in the early $\mathrm{Rp}+$ group $(M=-.40)$ $[t(18)=6.44, p<.001]$, indicating that the retrievalinduced forgetting effect detected at the second test was due to output interference operating at recall. In the 24-h delay condition, no significant differences were detected between the early Rp - group $(M=-1.67)$ and the early $\mathrm{Rp}+$ output group $(M=4.33)[t(18)=0.72$, n.s.].

Vividness and retrieval-induced forgetting. Vividness ratings were also examined in order to determine whether vivid image was related to level of retrievalinduced forgetting effect (i.e., no-delay and retest conditions). In the no-delay condition, high imagers $(M=-.31)$ demonstrated a slightly larger retrieval-induced forgetting effect than did low imagers $(M=-.28)$, but this difference did not reach significance $[t(18)=0.37$, n.s. $]$. A similar pattern was observed for the first test (low imagers, $M=$ -.32; high imagers, $M=-.33)[t(18)=0.31$, n.s. $]$ and second test (low imagers, $M=-.25$; high imagers, $M=$ -.27) $[t(18)=0.22$, n.s. $]$ in the retest condition.

\section{Discussion}

The results of Experiment 3 replicate the findings that a 24-h delay abolishes the retrieval-induced forgetting effect (Carroll et al., 2007; MacLeod \& Macrae, 2001; Saunders \& MacLeod, 2002) and that pre-delay and post-delay tests maintain the effect (Migueles \& GarcíaBajos, 2007; Storm et al., 2006). These results suggest that methodological differences between studies on delay can explain some of the different findings across studies. Specifically, the presence of a pre-delay test may maintain the retrieval-induced forgetting effect across longer delays. One possible reason for the maintenance of retrievalinduced forgetting is that there may be a contribution of output interference to the effect: Participants may be more likely to remember the stronger $\mathrm{Rp}+$ items first, leading to a contribution of output interference at test. The finding 
of retrieval-induced forgetting may, therefore, be partly due to the earlier output of $\mathrm{Rp}+$ items at test's blocking the weaker $\mathrm{Rp}-$ items. It must be noted, however, that García-Bajos et al. (2009) still found retrieval-induced forgetting after 1 week - even though no pretest delay was used - and output interference was discounted as a possible explanation for retrieval-induced forgetting. Thus, the findings of García-Bajos et al. suggest that pre-delay tests and output interference are not the only explanations for retrieval-induced forgetting persisting at longer delays and that temporary forgetting is not an inherent property of retrieval-induced forgetting.

\section{EXPERIMENT 4 Mental Imagery of Actions}

In the present Experiments 1, 2, and 3, we utilized simple word lists of semantic categories. In Experiment 4, we attempted to apply mental imagery to more complex episodic materials. Specifically, in Experiment 4, participants were asked to imagine a subset of actions performed either by themselves (i.e., first-person perspective) or by another individual (i.e., third-person perspective). These two conditions were compared with a postevent questioning condition, because questioning is a known retrievalbased task that initiates retrieval-induced forgetting (MacLeod, 2002; Shaw et al., 1995).

\section{Method}

Participants and Design. One hundred twenty-six students from Swansea University participated in exchange for $£ 5$. The experiment had a 3 (practice task: first-person perspective, third-person perspective, or postevent questioning) $\times 3$ (item type: $\mathrm{Rp}+, \mathrm{Rp}-$, or Nrp) mixed design with repeated measures on the latter factor. Each condition contained 42 participants.

Materials. Participants were required to read two narratives: one concerning a burglary and one concerning a car accident. Both stories were narrated in the third person (see Appendix C). Each narrative contained 10 target items that were selected through earlier pilot work, in which we determined that these items were highly likely to be encoded during the study phase $(n=15)$.

During postevent questioning, participants were issued a list of questions about half of the target items from one of the events (e.g., "What brand of laptop does the burglar steal from the living room?"). Participants were questioned about these same five items across three phases of questioning. Each phase was interleaved with an expanding distractor task: Participants completed a 1-min distractor task after the first set of questions, a 2-min distractor task after the second set, and a 3-min distractor task after the final set. Counterbalancing ensured that each item appeared equally as often as a response to a question.

For each target item, we generated mental imagery cues that required the participants to imagine either themselves or the individual from the event performing actions and interacting with target items from a first- or third-person perspective, respectively. For example, in the first-person perspective condition, participants were asked to "imagine you are looking round the room for something worth stealing and you spot an electric razor. You think it may make some money so you decide to put it into your bag." In the third-person perspective condition, this same item might require the participant to "imagine that you can see him looking round the room for something to steal. You see that he has spotted an electric razor. You see him pick it up and put it into his bag." Participants received mental imagery prompts about five items from one event and formed mental imagery for each item across three phases of mental imagery tasks (i.e., mental imagery was formed for each item three times). Each mental imagery phase was interleaved with distractor tasks using the same method as for postevent questioning. Counterbalancing ensured that each item appeared equally as often in the mental imagery prompts. For every mental imagery prompt, participants were asked to rate the vividness of their mental imagery and the ease of forming mental imagery on a scale from 0 (easy) to 100 (difficult).

Procedure. The participants were asked to read two narratives: one concerning a car accident and one concerning a burglary. Order of presentation of narratives was counterbalanced, and the participants read through each narrative at their own pace. Following study, the participants completed the postevent phases relevant to their condition. In the postevent questioning condition, the participants were presented with written questions about five items from one event and were asked to record their answers on a sheet provided. In the mental imagery conditions, the participants were given written mental imagery prompts concerning five items from one event. They were asked to read the mental imagery prompts and to imagine either performing actions and interacting with the target item from a first-person perspective or observing the individual from the event performing the actions. After each prompt, the participants rated the vividness of their mental imagery and the ease with which they had formed mental imagery for each scenario.

All of the groups received their tasks three times, interleaved with distractor tasks (i.e., anagrams) at 1-, 2-, and 3-min intervals between tasks. Upon completion of the final distractor task, the participants were asked to try to recall as many details about both stories as possible (i.e., category cued recall). Order of recall from each story was counterbalanced.

\section{Results}

During the mental imagery task, the participants indicated the ease with which they had formed mental imagery for each task, and they rated the vividness of the imagery. For the first-person perspective condition, mean vividness was .74, and mean ease was .75; in the thirdperson perspective condition, mean vividness was .71, and mean ease was .73. No differences were detected between the first- and third-person perspective conditions for vividness $[t(82)=0.87$, n.s. $]$ or ease $[t(82)=0.70$, n.s. $]$. The success rate for answering questions correctly in the postevent questioning condition was 89 .

Facilitation effects. In order to determine whether mental imagery facilitates memory performance in a manner similar to postevent questioning, a 3 (practice task: firstperson perspective, third-person perspective, or postevent questioning) $\times 2$ (item type: Rp + or Nrp) mixed ANOVA was performed (see Table 3 for mean recall performance). This analysis revealed a main effect of item type $[F(1,123)=$ $\left.156.50, p<.001, \eta^{2}=.55\right]$. No interaction between item

Table 3

Mean Recall Performance by Condition, As a Function of Item Type in Experiment 4

\begin{tabular}{|c|c|c|c|c|c|c|c|}
\hline \multirow[b]{3}{*}{ Practice Task } & \multicolumn{6}{|c|}{ Item Type } & \multirow{3}{*}{$\begin{array}{l}\text { Retrieval- } \\
\text { Induced } \\
\text { Forgetting* }\end{array}$} \\
\hline & \multicolumn{2}{|c|}{$\mathrm{Rp}+$} & \multicolumn{2}{|c|}{$\mathrm{Rp}-$} & \multicolumn{2}{|c|}{ Nrp } & \\
\hline & $M$ & $S D$ & $M$ & $S D$ & $M$ & $S D$ & \\
\hline First-person perspective & .82 & .18 & .50 & .26 & .60 & .18 & -.10 \\
\hline Third-person perspective & .90 & .15 & .51 & .23 & .62 & .17 & -.11 \\
\hline Postevent questioning & .83 & .19 & .51 & .22 & .62 & .16 & -.11 \\
\hline
\end{tabular}

Note- $\mathrm{Rp}+$, practiced items from practiced categories; $\mathrm{Rp}-$, unpracticed items from practiced categories; Nrp, unpracticed items from unpracticed categories. ${ }^{*}(\mathrm{Rp}-)-\mathrm{Nrp}$. 
type and condition was detected $[F(2,123)=1.32$, n.s. $]$, indicating that all forms of practice (i.e., imagination and postevent questioning) facilitated memory performance. Paired-samples $t$ tests confirmed this pattern of higher recall performance for $\mathrm{Rp}+$ items $(M=.82)$, as compared with that for the Nrp baseline $(M=.60)$, following firstperson imagination $[t(41)=6.74, p<.001]$, third-person imagination (for $\mathrm{Rp}+, M=.90$; for $\mathrm{Nrp}, M=.62)[t(41)=$ $9.15, p<.001]$, and postevent questioning (for $\mathrm{Rp}+, M=$ .83 ; for Nrp, $M=.62)[t(41)=6.01, p<.001]$.

Retrieval-induced forgetting effects. To establish whether practice also initiated retrieval-induced forgetting, a 3 (practice task: first-person perspective, third-person perspective, or postevent questioning) $\times 2$ (item type: $\mathrm{Rp}-$ or Nrp) mixed ANOVA was performed. This revealed a main effect of item type $\left[F(1,123)=20.36, p<.001, \eta^{2}=.14\right]$. No interaction between item type and condition was detected $[F(2,123)=0.04$, n.s.], suggesting that all forms of practice elicited impairment in $\mathrm{Rp}$ - performance. Pairedsamples $t$ tests confirmed that significantly fewer Rpitems were reported following first-person imagination $(M=.50)[t(41)=-2.20, p<.05]$, third-person imagination $(M=.51)[t(41)=-3.20, p<.01]$, and postevent questioning $(M=.51)[t(42)=-2.61, p<.01]$.

Output interference. Performance in each of the conditions was checked for the influence of output interference. In the first-person condition, the average retrievalinduced forgetting effect was -.12 in the early $\mathrm{Rp}-$ output group and -.08 in the early $\mathrm{Rp}+$ group; no significant differences were detected between the two groups $[t(18)=0.64$, n.s.]. In the third-person condition, the average retrieval-induced forgetting effect was -.09 in the early $\mathrm{Rp}-$ output group and -.13 in the early $\mathrm{Rp}+$ group; no significant differences were detected between the two groups $[t(18)=0.48$, n.s.]. Finally, in the postevent questioning condition, the average retrieval-induced forgetting effect was -.11 in the early $\mathrm{Rp}-$ output group and -.08 in the early $\mathrm{Rp}+$ group; no significant differences were detected between the two groups $[t(18)=0.44$, n.s.].

Vividness and retrieval-induced forgetting. Vividness ratings were examined to determine whether high imagers produced a larger retrieval-induced forgetting effect than that produced by low imagers. Little difference was found between low $(M=-.10)$ and high $(M=-.11)$ imagers in the first-person imagination condition $[t(40)=$ 0.16, n.s.] or between low $(M=-.12)$ and high $(M=$ $-.09)$ imagers in the third-person condition $[t(40)=$ 0.49, n.s.].

\section{Discussion}

The fact that selective mental imagery facilitated memory for visualized details and impaired memory for relatedbut-nonvisualized details suggests that mental imagery has memory-modifying capabilities. In order to examine whether retrieval-based processes were responsible for the memory-modifying properties of mental imagery, we compared performance of first-person and third-person perspective mental imagery with postevent questioning, which is a retrieval task known to be capable of facilitating memory for questioned items and initiating retrieval-induced for- getting for nonquestioned details from questioned events. Levels of facilitation for visualized items were found to be comparable to those of questioned items, suggesting that the act of forming mental imagery about an episodic event requires the retrieval of to-be-visualized information from long-term memory. Likewise, the magnitude of retrievalinduced forgetting initiated for nonvisualized details from visualized events was comparable to that for nonquestioned items from questioned events. First-person perspective, third-person perspective, and postevent questioning were all susceptible to retrieval-induced forgetting, suggesting that all three tasks are capable of leading to competition for retrieval among target items and related-but-unwanted information. In order to resolve retrieval competition so that the target may be produced, retrieval-induced forgetting was initiated, leading to a reduction in later memory performance for related-but-unwanted information. Thus, the finding that both first-person and third-person perspective mental imagery can initiate retrieval competition among target and related information resulting in retrieval-induced forgetting effects comparable to that of postevent questioning suggests that the process by which mental imagery can modify memory is retrieval-based in nature.

\section{GENERAL DISCUSSION}

Previous research has suggested that selective retrieval of target memories can lead to impaired recall of the remaining unretrieved category members (Anderson et al., 2000; Anderson et al., 1994; MacLeod \& Macrae, 2001; Macrae \& MacLeod, 1999). Retrieval-induced forgetting has been found to occur in semantic memory (Johnson \& Anderson, 2004), in episodic materials (Ciranni \& Shimamura, 1999), in eyewitness memory (MacLeod, 2002; Shaw et al., 1995), autobiographical information (Barnier et al., 2004), and second-language acquisition (Levy et al., 2007), to name a few. To this list, we can now add mental imagery. Across four experiments, mental imagery of semantic (Experiments 1, 2, and 3) and episodic (Experiment 4) target information led to retrieval-induced forgetting for the remaining nonvisualized details.

The present findings are consistent with an inhibitory account of mental imagery. In Experiment 1, memory performance among mental imagery, retrieval practice, and re-presentation were directly compared, thus providing a test of the inhibitory account. Retrieval-induced forgetting was found to occur for mental imagery and retrieval practice, but not for re-presentation, despite the mental imagery task's requiring re-presentation of the cue-exemplar pair. This pattern of findings suggests that inhibition (i.e., retrieval-induced forgetting) occurs only when overly general retrieval cues are used during practice. These overly general retrieval cues may activate the target to-bevisualized items plus related-but-unwanted information. For example, when one visualizes the color of an apple, other red or green objects may come to mind. In order to facilitate the retrieval of the desired information for visualization, inhibitory processes may be activated in order to resolve unwanted competition emanating from related information. The finding in Experiment 1 -that retrieval- 
induced forgetting occurs for mental imagery but not for re-presentation - suggests that the underlying retrieval processes of selective imaginings also initiate inhibitory processes.

Mental imagery may initiate retrieval-induced forgetting due to the act of generating images or to the process of generating images. The former is a less specific claim; it suggests that the act of generating images requires access to semantic knowledge in long-term memory. The act of semantic generation is known to initiate retrievalinduced forgetting (Bäuml, 2002; Storm et al., 2006), and this account of mental imagery-initiated, retrievalinduced forgetting would suggest that there are no unique properties concerning mental imagery and that it is just another form of semantic (Experiments 1, 2, and 3) or episodic (Experiment 4) generation. The latter point suggests that retrieval-induced forgetting is the outcome of the process of forming mental imagery. This "process" account suggests that retrieval-induced forgetting could be specifically tied to the process of forming mental imagery and would occur after the initial generation of knowledge from long-term memory. The present experiments did not test between these two accounts. There is evidence from the retrieval-induced forgetting literature, however, to support the account that it is the act of forming mental imagery that initiates retrieval-induced forgetting (Bäuml \& Hartinger, 2002). Specifically, semantic generation is a known initiator of retrieval-induced forgetting, and mental imagery may, therefore, be just a visual-based form of semantic generation.

There may also be interactions between the semantic and episodic generation of details in Experiment 4. In the imagination tasks, participants were asked to imagine themselves performing a series of actions on objects in an event that they had recently read. Some of the details being imagined may have been generated from semantic memory (e.g., what the rucksack that the burglar owned looked like), whereas other details may have been generated from episodic memory (e.g., actions mentioned in the stories). Both semantic and episodic generation may have led to retrieval-induced forgetting for nonimagined details from the imagined scenario.

Episodic generation may also have contributed to the patterns of results in Experiments 1, 2, and 3. Although each mental imagery task required different aspects of the same object to be visualized, it is possible that participants may have visualized other aspects of the object. For example, when one visualizes the shape of a rose, he or she may visualize the color and size of the rose as well. Thus, participants' later visualization of color and size may rely on the earlier, complete visual image produced during the first task.

If the retrieval processes underlying mental imagery can initiate retrieval-induced forgetting, but re-presentation does not, it suggests that other tasks may also invoke retrieval-induced forgetting. Any task that utilizes covert or overt retrieval from semantic or episodic memory is likely to induce forgetting. For example, elaboration, which could require semantic generation, may use retrieval processes and may, thus, initiate retrieval-induced forgetting. Conversely, any task that does not utilize covert or overt retrieval processes is unlikely to invoke retrievalinduced forgetting. For example, extra study time and rote rehearsal are unlikely to initiate retrieval-induced forgetting; these forms of re-presentation present individuals with sufficient cue-related information to allow for the successful retrieval of the target. That is, these forms of representation are unlikely to raise levels of retrieval competition between the target and related items.

It should also be noted that, in Experiment 1, the mental imagery-initiated, retrieval-induced forgetting effect was much larger $(-.31)$ than that produced via standard retrieval practice $(-.17)$. One possible explanation for this finding relates to the instructions given in the mental imagery tasks. Although participants in the mental imagery and retrieval practice conditions were instructed to practice the same item across four practice tasks, the participants in the mental imagery condition generated different aspects of the same object. Specifically, in the mental imagery condition, participants were prompted to imagine four different pieces of sensory information about the same object; in the retrieval practice condition, participants were required to repeatedly retrieve the same name of an object of animal. Thus, during selective mental imagery, this may have led to the inhibition of different features related to the same item (e.g., color, shape, texture, etc.), perhaps resulting in a cumulative inhibitory effect in semantic and episodic memory. Conversely, selective retrieval practice may have led to inhibition of only the word in semantic memory.

In conclusion, in the present four experiments, we have demonstrated that the retrieval processes underlying mental imagery can initiate retrieval-induced forgetting. Mental imagery not only increases memorability of visualized items but can also make it harder to remember nonvisualized items that are related to visualized items. This retrieval-induced forgetting effect is found with free recall and cued recall tasks, irrespective of whether the information is imagined in the first or third person.

\section{AUTHOR NOTE}

We acknowledge the support of a grant from the Leverhulme Trust to the first author. Correspondence concerning this article should be addressed to J. Saunders, Department of Psychology, University of Swansea, Singleton Park, Swansea SA2 8PP, Wales (e-mail: j.saunders@) swan.ac.uk).

\section{REFERENCES}

Anderson, M. C. (2001). Active forgetting: Evidence for functional inhibition as a source of memory failure. Journal of Aggression, Maltreatment, \& Trauma, 4, 185-210.

Anderson, M. C., \& Bell, T. A. (2001). Forgetting our facts: The role of inhibitory processes in the loss of propositional knowledge. Journal of Experimental Psychology: General, 130, 544-570.

Anderson, M. C., BJork, E. L., \& BJork, R. A. (2000). Retrievalinduced forgetting: Evidence for a recall-specific mechanism. Psychonomic Bulletin \& Review, 7, 522-530.

Anderson, M. C., BJork, R. A., \& BJork, E. L. (1994). Remembering can cause forgetting: Retrieval dynamics in long-term memory. Journal of Experimental Psychology: Learning, Memory, \& Cognition, 20, 1063-1087.

Anderson, M. C., \& Spellman, B. A. (1995). On the status of inhibitory mechanisms in cognition: Memory retrieval as a model case. Psychological Review, 102, 68-100.

Barnier, A. J., Hung, L., \& Conway, M. A. (2004). Retrieval-induced 
forgetting of emotional and unemotional autobiographical memories. Cognition \& Emotion, 18, 457-477.

BÄUML, K.-H. (2002). Semantic generation can cause episodic forgetting. Psychological Science, 13, 357-361.

BäUML, K.-H., \& HARTINGER, A. (2002). On the role of item similarity in retrieval-induced forgetting. Memory, 10, 215-224.

BJORK, R. A., \& BJORK, E. L. (1992). A new theory of disuse and an old theory of stimulus fluctuation. In A. F. Healy, S. M. Kosslyn, \& R. M. Shiffrin (Eds.), Essays in honor of William K. Estes: Vol. 2. From learning processes to cognitive processes (pp. 35-67). Hillsdale, NJ: Erlbaum.

Camp, G., Pecher, D., \& Schmidt, H. G. (2005). Retrieval-induced forgetting in implicit memory tests: The role of test awareness. Psychonomic Bulletin \& Review, 12, 490-494.

Carroll, M., Campbell-Ratcliffe, J., Murnane, H., \& Perfect, T. J. (2007). Retrieval-induced forgetting in educational contexts: Monitoring, expertise, text integration, and test format. European Journal of Cognitive Psychology, 19, 580-606.

Ciranni, M. A., \& Shimamura, A. P. (1999). Retrieval-induced forgetting in episodic memory. Journal of Experimental Psychology: Learning, Memory, \& Cognition, 25, 1403-1414.

Conroy, R., \& Salmon, K. (2005). Selective postevent review and children's memory for nonreviewed materials. Journal of Experimental Child Psychology, 90, 185-207.

ConRoy, R., \& SALMON, K. (2006). Talking about parts of a past experience: The impact of discussion style and event structure on memory for discussed and nondiscussed information. Journal of Experimental Child Psychology, 95, 278-297.

Ford, R. M., Keating, S., \& Patel, R. (2004). Retrieval-induced forgetting: A developmental study. British Journal of Developmental Psychology, 22, 585-603.

García-Bajos, E., Migueles, M., \& Anderson, M. C. (2009). Script knowledge modulates retrieval-induced forgetting for eyewitness events. Memory, 17, 92-103.

Johnson, S. K., \& ANDERson, M. C. (2004). The role of inhibitory control in forgetting semantic knowledge. Psychological Science, 15, 448-453.

LANDAUER, T. K., \& BJORK, R. A. (1978). Optimum rehearsal patterns and name learning. In M. M. Gruneberg, P. E. Morris, \& R. N. Sykes (Eds.), Practical aspects of memory (pp. 625-632). New York: Academic Press.
Levy, B. J., McVeigh, N. D., Marful, A., \& Anderson, M. C. (2007). Inhibiting your native language: The role of retrieval-induced forgetting during second-language acquisition. Psychological Science, 18, 29-34.

MACLEOD, M. D. (2002). Retrieval-induced forgetting in eyewitness memory: Forgetting as a consequence of remembering. Applied Cognitive Psychology, 16, 135-149.

MacLeod, M. D., \& Macrae, C. N. (2001). Gone but not forgotten: The transient nature of retrieval-induced forgetting. Psychological Science, 12, 148-152.

MacLeod, M. D., \& Saunders, J. (2005). The role of inhibitory control in the production of misinformation effects. Journal of Experimental Psychology: Learning, Memory, \& Cognition, 31, 964-979.

Macrae, C. N., \& MacLeod, M. D. (1999). On recollections lost: When practice makes imperfect. Journal of Personality \& Social Psychology, 77, 463-473.

MARKS, D. F. (1973). Visual imagery differences in the recall of pictures. British Journal of Psychology, 64, 17-24.

Migueles, M., \& García-BaJos, E. (2007). Selective retrieval and induced forgetting in eyewitness memory. Applied Cognitive Psychology, 21, 1157-1172.

RoEDiger, H. L., III, \& Schmidt, S. R. (1980). Output interference in the recall of categorized and paired-associate lists. Journal of Experimental Psychology: Human Learning \& Memory, 6, 91-105.

SAUNDERS, J. (2009). Memory impairment in the weapon focus effect. Memory \& Cognition, 37, 326-335.

Saunders, J., \& MacLeod, M. D. (2002). New evidence on the suggestibility of memory: The role of retrieval-induced forgetting in misinformation effects. Journal of Experimental Psychology: Applied, $\mathbf{8}, 127-142$

SAUnders, J., \& MacLeod, M. D. (2006). Resolving competition at retrieval through the controlling of spreading activation: A possible role for inhibitory processes in memory. Memory \& Cognition, 34, 307-322.

ShaW, J. S., III, BJork, R. A., \& Handal, A. (1995). Retrieval-induced forgetting in an eyewitness-memory paradigm. Psychonomic Bulletin \& Review, 2, 249-253.

SNEDECOR, G. W., \& Cochran, W. G. (1980). Statistical methods (7th ed.) Ames, IA: Iowa State University Press.

Storm, B. C., BJork, E. L., BJork, R. A., \& Nestojko, J. F. (2006). Is retrieval success a necessary condition for retrieval-induced forgetting? Psychonomic Bulletin \& Review, 13, 1023-1027.

\section{APPENDIX A}

Study Materials in Experiments 1, 2, and 3

\begin{tabular}{ll}
\hline \multicolumn{1}{c}{ Category } & \multicolumn{1}{c}{ Items } \\
\hline $\begin{array}{l}\text { Sports equipment } \\
\text { Tools }\end{array}$ & $\begin{array}{l}\text { bowling pin, boxing glove, football, hockey stick, tennis racket, swimming goggles } \\
\text { screwdriver, drill, handsaw, pitchfork, pliers, wrench } \\
\text { Bird }\end{array}$ \\
Seagull, budgie, crow, penguin, mallard, parrot \\
bomb, cannon, grenade, rifle, tank, sword \\
Flower & $\begin{array}{l}\text { cactus, carnation, daffodil, tulip, daisy, rose } \\
\text { champagne, coffee, tea, red wine, martini, beer }\end{array}$ \\
Frinks & $\begin{array}{l}\text { cherries, orange, banana, pear, strawberry, apple } \\
\text { Fruit }\end{array}$ \\
Musical instrument & drums, flute, French horn, guitar, harp, piano \\
\hline
\end{tabular}

\section{APPENDIX B}

Mental Imagery Tasks in Experiments 1, 2, and 3

1. Please form a mental image of the shape of this item.

2. Please form a mental image of the color of this item.

3. Please form a mental image of the size of this item.

Plus one of the following:

Please form a mental image of the sound that this item makes.

Please form a mental image of the texture of this item on your hands.

Please form a mental image of the weight of this item in your hands.

Please form a mental image of the smell of this item.

Please form a mental image of the texture of this item on your hands.

Please form a mental image of the taste of this item on your tongue. 


\section{APPENDIX C \\ Study Materials in Experiment 4}

Target items are italicized.

\section{Burglary Story}

A burglar breaks into a semi-detached house. He breaks the window of the downstairs bathroom, pushes out the shards of glass and reaches in to open the latch. He climbs through the window, steadying himself on the sink. The only thing he sees worth taking is an electric razor, which he puts into his backpack. He slowly makes his way through the hallway, looking through the first doorway into the kitchen, deciding it would have nothing he could take he moves on.

He continues down the hall and opens the next door a little to look in and sees that it's the living room. He goes in and shines his torch around the room and sees a huge wide screen Sony TV. He'd love to steal it but decides he'd never be able to carry it and certainly not make a quick getaway with it!

He notices a Dell laptop and a collection of Bob Marley CDs which he takes and puts in his back pack.

The burglar then goes out the door and up the stairs, the first door he comes to upstairs is the main bedroom. He goes in and finds a jewelry box; he finds a delicate diamond ring and a silver necklace with a sapphire pendant. He takes both of these, and also a $£ 20$ note he finds on the dresser.

The burglar looks in the next room and seeing it's a child's bedroom has just enough decency not to take anything from it.

He then heads down the stairs and lets himself out the back door.

\section{Car Crash Story}

A man emerges from his usual pub, "The Royal Oak" after having 5 pints of beer with his lunch. He walks to the car park and approaches a red Fiesta. He takes his keys out of his pocket and unlocks the car door.

The man gets into his car and enjoys the warm feeling of the leather on the seats as the car has been sat in the sun. He puts the keys in the ignition and starts the car. He drives through the pub car park, being extra careful to obey the one-way system, as he is aware of having drunk too much at lunchtime.

The man pulls out of the car park and onto a main road with a $40 \mathrm{mph}$ speed limit. He accelerates up to the speed limit and then thinks he may as well push it up to 50mph as he feels totally in control of the car and thinks that he can't have drunk as much as he thought.

The man decides he wants to listen to some music, so with one hand on the steering wheel he reaches across to the passenger seat for a tape he thinks he left there. Finding nothing he likes, the man looks back up at the road. He looks up just in time to notice there is a queue of 5 cars up ahead waiting at traffic lights. The driver slams on the brakes, but doesn't manage to slow in time, he slams straight into the back of the white car in front, which in turn hits the blue car in front of it and so on like dominoes causing a 5-car pile up.

The driver then, fully aware of the consequences if he is caught with alcohol in his system, accelerates away. He is not seriously injured although the force of knocking into the car in front caused him to hit his head on the steering wheel and gave him a nasty cut just above his left eye. 